\title{
A Problemática da Representação Social e sua Utilidade no Campo da Doença ${ }^{1}$
}

CLAUDINE HERZLICH ${ }^{2}$

Partindo do conceito de representação social, tal como proposto por Durkheim, a autora, focalizando a produção francesa a partir dos anos 60, se dispõe a rever os modos pelos quais a noção foi atualizada no campo da saúde. Ainda que salientando algumas limitações teóricas subjacentes ao uso do conceito, Herzlich argumenta em favor de sua persistente fecundidade enquanto marco analítico para se pensar os fenômenos da saúde e da doença. Sugere, nesse sentido, alguns possíveis desdobramentos teóricos ensejados pela utilização do conceito nesse campo específico.

Palavras-chave: Representação social; saúde; doença. 
O termo "representação social", ou "representação coletiva" foi proposto, como é sabido, por Durkheim, que desejava enfatizar a especificidade e a primazia do pensamento social em relação ao pensamento individual ${ }^{3}$. Para esse autor, assim como a representação individual deve ser considerada um fenômeno psíquico autônomo não redutível à atividade cerebral que a fundamenta, a representação coletiva não se reduz à soma das representações dos indivíduos que compõem a sociedade. Ela é também uma realidade que se impõe a eles: "as formas coletivas de agir ou pensar têm uma realidade fora dos indivíduos que, em cada momento, conformam-se a elas. São coisas que têm existência própria. $\mathrm{O}$ indivíduo as encontra formadas e nada pode fazer para que sejam ou não diferentes do que são"4.

Em 1961, a publicação da obra de Moscovici sobre a representação social da psicanálise deu nova vida a essa noção. No entanto, cometeríamos um erro se situássemos esse trabalho em uma linhagem durkheimiana estrita. Certamente, a tentativa partia da hipótese da existência de um papel primeiro, de um fato global, da sociedade: o homem é um ser social, formado em particular pela língua da sociedade à qual pertence, modelado por um universo cognitivo e simbólico que lhe é, de fato, preexistente. Um dos objetivos de Moscovici era exatamente reintroduzir, num domínio que tendia a ignorá-la, essa dimensão social no sentido pleno. No entanto, seu interesse principal ia menos no sentido da determinação - ou seja, da estruturação pela sociedade dos fenômenos da representação - do que no sentido da construção da realidade que se opera através desses fenômenos e dos quais os sujeitos sociais são também autores.

Encontramos aí talvez o problema mais comum - mas também dos mais difíceis - das Ciências Sociais: a influência recíproca da estrutura social e do autor. A noção de representação social, tal como Moscovici procurou elaborar, constituiu uma tentativa de articulá-los. Mas sem dúvida a ênfase era colocada sobretudo num lado: a reflexão se apoiava mais no sujeito ativo, construtor do mundo a partir dos materiais que a sociedade lhe fornece, do que na própria estrutura social.

É preciso situar esse trabalho em seu contexto. De fato, para Moscovici, o estudo de uma representação social situava-se no campo de uma psicologia social, dominada então pela tradição behaviorista: a de uma ligação direta entre estímulos e resposta comportamental. Face a esse modelo, tratava-se de introduzir a noção de uma atividade organizadora sobre o duplo plano cognitivo e simbólico; atividade organizadora de um grupo, ou de um indivíduo enquanto 
membro de um grupo, que orienta a resposta, já que ela estrutura o estímulo e lhe dá um sentido coletivamente partilhado.

Mais precisamente, no caso da representação social da psicanálise, o problema era ver como, através da assimilação dos conceitos psicanalíticos, os sujeitos sociais construiriam uma nova realidade da vida psíquica, a sua e a dos outros. As noções provenientes da psicanálise - o "inconsciente" ou os "complexos", por exemplo - tornaram-se categorias do entendimento e da linguagem,exprimindo, para aqueles que a usam, uma evidência imediata. Uma comunicação foi construída, um acordo foi feito, em torno de um modelo abstrato que se transformou em experiência direta. No fim dos anos50, começava-se a perceber, sem ambigüidade, em torno de cada um, inconscientes infelizes, recalques nascentes e complexos antigos. Essa construção de uma evidência até então desconhecida - mas, por princípio, considerada "natural" e ordenada por uma significação, central, o da todo-poderosa sexualidade - constituiu o eixo primeiro da conceitualização.

O segundo ponto de referência do estudo é, sem dúvida, o processo pelo qual uma representação social é um modo de pensamento sempre ligado à $a c ̧ \tilde{a} o$, à conduta individual e coletiva, uma vez que ela cria ao mesmo tempo as categorias cognitivas e as relações de sentido que são exigidas.

O terceiro procura dar conta do fato de uma representação social poder funcionar como atributo de um grupo: ou seja, grupos sociais podem identificarse, perceber-se, aliar-se ou rejeitar-se através dela. $\mathrm{O}$ último ponto importante, mas que só é anunciado como hipótese a aprofundar - o da "polifasia cognitiva" - refere-se à coexistência complexa, numa sociedade como a nossa, de discursos de origens múltiplas e funcionamentos diversos, fundindo-se, diferenciandose ou excluindo-se, segundo as circunstâncias.

No entanto, a meu ver, a escolha da psicanálise como objeto de estudo colocou um problema. À primeira vista, talvez fosse mais ilustrativo estudar mecanismos de uma representação social a partir da existência de um modelo externo bem demarcado e surgido recentemente no campo social: o dos escritos freudianos. Mas, por um lado, sabemos - e Daniel Lagache o indicou em seu prefácio à obra - que há em Freud muitos modelos sobre a vida psíquica. Por outro lado, se é evidente que a representação social tem sempre uma ou mais origens em elaborações de natureza diversa -, a existência da psicanálise como teoria científica introduz, no entanto, uma ambigüidade entre os mecanismos de funcionamento de uma representação e os da difusão de uma teoria científica. 
Donde a compreensão reducionista que se tem às vezes desse livro: o estudo do que as pessoas "sabem" da psicanálise ou daquilo que elas "pensam".

Em trabalho (HERZLICH, 1969) realizado após o de Moscovici, procurei escapar dessa ambigüidade: para mim foi essencial estudar as representações de saúde e doença como realidade sui generis, fora dos modelos médicos. Nesse nível, minha inspiração situava-se na linha de trabalhos antropológicos - convergindo, aliás, com a idéia durkheimiana de um " "pensamento social" - que mostram a existência, em cada sociedade, de um discurso sobre a doença que não é independente do conjunto dessas construções mentais de expressão. Por vezes, ele é uma via de acesso privilegiado ao conjunto de suas concepções, de seus valores e de suas relações de sentido. Tratava-se, portanto, de mostrar que, qualquer que fosse a importância da medicina moderna, a doença é um fenômeno que a ultrapassa (HERZLICH, 1984) e que a representação não é apenas esforço de formulação mais ou menos coerente de um saber, mas também interpretação e questão de sentido. Retrospectivamente, tal me parece ter sido a contribuição principal desse trabalho: através da análise da gênese da doença, imputada à sociedade agressiva e opressora, atribuída a um "modo de vida" moderno e urbano, "malsão", imposto ao indivíduo (que se identifica à saúde), pude mostrar como a interpretação coletiva dos estados do corpo colocava em questão, no sentido próprio, a ordem social. Nossas visões do biológico e do social apareciam, assim, relacionadas entre si, tal como podemos encontrar, sob outras formas, em numerosas sociedades. Na mesma época, Mary Douglas (1966) analisou de que forma as concepções sobre poluição, e os tabus e os rituais que lhes são associados, correspondem também a uma socialização e mesmo a uma politização do "natural" nas sociedades tradicionais.

Dito de outra forma, a dupla oposição "saúde-doença" e "indivíduosociedade", que organiza a representação, dá sentido à doença. "Por meio da saúde e da doença, temos acesso à imagem da sociedade, de suas "imposições", tais como o indivíduo as vive. Englobada nesta imagem, a doença adquire uma significação", escrevi na conclusão do estudo. "Para nós, como para os primitivos, é provavelmente importante que a doença, se ela é desordem, não seja acaso; é provavelmente importante que, enquanto desordem, ela seja significativa. Ela encarna a 'imposição social'" (HERZLICH, 1981, p. 177). Mais tarde, Susan Sontag (1977) formularia idéias parecidas, sob a bela expressão "doença como metáfora". 
Sobre outro plano, o estudo procedeu a uma análise das categorias, das oposições, dos agenciamentos cognitivos e das formas de racionalidade - nas quais podem ser encontrados empréstimos de registros diversos - com os quais os sujeitos tentam traduzir e organizar, para o investigador, sua experiência. A análise foi dirigida, neste caso, para o funcionamento do entendimento cotidiano e para a construção da evidência: construção social da realidade supostamente mais natural, a da doença, do corpo e de suas manifestações. Enfim, o livro terminou com a elaboração de modelos de conduta cujo interesse essencial residia no caráter integrador: encontra-se aí a idéia de que a representação tem função orientadora das condutas.

Simplificando um pouco, as críticas dirigidas a esses primeiros estudos sobre as representações sociais foram de três ordens. Por parte dos psicossociólogos, a principal questão colocada foi a do caráter muito geral, pouco mensurável, da representação e de sua articulação com o comportamento individual: pode-se estabelecer uma relação direta, preditiva, como foi tentado a propósito das atitudes entre uma representação e um comportamento individual?

Parece-me evidente que a resposta a essa questão é negativa ${ }^{5}$ : não pode haver ligação mecânica entre uma representação coletiva e uma conduta individual específica. Sem dúvida, em situação experimental, os psicólogos sociais puderam demonstrar um impacto nítido sobre a resposta dos sujeitos, pela indução de diversos tipos de representação ${ }^{6}$. Entretanto, é claro que representações diferentes podem atualizar-se em condutas semelhantes e que uma representação partilhada coexiste com comportamentos muito diferentes. No campo da saúde, um artigo de Pierre Aiach mostra claramente a complexidade das relações que podem ser estabelecidas entre esses dois níveis, sem dúvida um dos problemas menos resolvidos nesse tipo de estudos (AIACH, 1981).

A meu ver, a predição de condutas individuais não é o objetivo dos estudos de representação, que me parece ser sobretudo evidenciar o código a partir do qual se elaboram significações ligadas às condutas individuais e coletivas. Deste ponto de vista, ressaltei ${ }^{7}$, o interesse no estudo de uma representação social deve situar-se no nível do esclarecimento de fenômenos mais coletivos. Uma representação social permite em princípio compreender por que alguns problemas sobressaem numa sociedade e esclarecer alguns aspectos de sua apropriação pela sociedade, como os debates e os conflitos 
que se desenrolam entre diferentes grupos de atores. Compreendemos de que forma chegam e constituem o foco de condutas múltiplas e complexas - tal o papel de orientação das representações; mas a explicação das condutas propriamente ditas deve incluir outras variáveis, e não apenas as representações ${ }^{8}$.

Os sociólogos apresentaram críticas a partir de outros pressupostos, mas, em certo sentido, elas coincidiam com as dos primeiros. Os de inspiração marxista (em seu conjunto) ignoraram esse tipo de estudo, que não cabia em seu esquema de interpretação, muito rígido, dos fenômenos ideológicos. Para os outros, a principal crítica referia-se à tentativa de atribuir, às representações dos sujeitos sociais, uma realidade e um papel autônomos. Sem dúvida, foram mais bem formuladas por P. Bourdieu, J. C. Passeron e J. C. Chamboredon, em Métier du sociologue, publicado em 1968: a partir de uma defesa contra o perigo do ressurgimento da "sociologia espontânea" na consciência sociológica, os autores detiveram-se em todos os estudos psicossociais nos quais de algum modo - e é bem o caso das representações sociais - o discurso dos sujeitos forma a base da análise.

Para esses autores, não seria possível explicar a ação ou o funcionamento de um sistema com base no sentido que a apreensão imediata dos atores individuais lhe atribui de forma espontânea. Para eles, "a descrição das atitudes, das opiniões e das aspirações individuais está longe de fornecer o princípio explicativo do funcionamento de uma organização; é a apreensão da lógica objetiva da organização que conduz ao princípio capaz de explicar, por acréscimo, as atitudes, as opiniões e as aspirações. Esse objetivismo provisório, que é condição para a apreensão da verdade objetivada dos sujeitos, é também condição para a compreensão completa da relação vivida que os sujeitos têm com sua verdade objetivada num sistema de relações objetivas" (BOURDIEU, PASSERON e CHAMBOREDON, 1968).

Devemos ser sensíveis a essa crítica. No entanto, até que ponto ela é aplicável à noção de representação social? Ela constitui um tipo de construção que, uma vez explicada, visa, de fato, a dar conta da linguagem, das categorias, das metáforas, presentes nos sujeitos que, para os autores, estão marcados pelo selo da evidência, e da evidência dotada de significado imediato. Mas não resulta disso, necessariamente, que o pesquisador também sucumba à ilusão de transparência dos sujeitos sociais. O objeto da representação parece, para os que dela partilham, pura e simples percepção: tal é seu caráter original.O pesquisador, quanto a ele, deve tentar articular em sua análise o fato de que a 
representação não constitui um simples reflexo do real, mas sua construção, que ultrapassa cada um individualmente e chega ao indivíduo, em parte, de fora dele.

Mas se pode notar também que, na mesma página de sua obra, os autores indicam logo os limites de sua posição objetivista-objetivismo provisório, afirmam - e a necessidade de reintroduzir o nível das significações. Retomando um texto anterior de P. Bourdieu, escrevem: "ao contrário da ciência da natureza, uma antropologia total não pode resumir-se a uma descrição das relações objetivas, porque a experiência das significações faz parte da significação

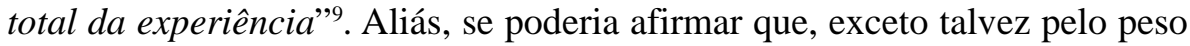
conferido ao passado, a noção de habitus não se afasta totalmente da de representação social.

No domínio da doença e da relação com o corpo, essa escola de pensamento pode ser ilustrada pelo conhecido trabalho de Luc Boltanski (1968). Ainda que não mantenha ao longo de seu texto uma posição estritamente objetivista, ele defende que o princípio explicativo do pensamento de senso comum sobre a doença reside, em particular, nas "classes baixas", no efeito de legitimidade produzido pelo discurso médico e na distância social que separa o médico e o doente. O discurso de senso comum, que procura dar conta da noção de representação social, é portanto desprovido de autonomia, constituído, diz Boltanski, de "materiais fragmentários e heteróclitos, palavras mal-entendidas e frases em pedaços, arrancadas do discurso do médico" (BOLTANSKI, 1968, p. 81). Mesmo reconhecendo que o efeito de legitimidade é insuficiente "para privar sujeitos sociais do discurso sobre a doença" (BOLTANSKI, 1968, p. 81), Boltanski nega que esse discurso tenha caráter de representação coletiva - portanto, de verdadeiro pensamento social - e vê como único interesse em seu estudo "as condições objetivas de sua produção, ou seja, do sistema de 'pressões' que o determina" (BOLTANSKI, 1968, p. 85).

Essa posição sempre me pareceu difícil de sustentar. O saber dos doentes é, de fato, pelo menos em parte, dependente do saber dos médicos: sobre esse plano, o estudo de Boltanski me parece válido. Contudo, isto não coloca em questão a existência, ou mesmo a autonomia, das representações, porque não se pode reduzi-las à pura reprodução de um saber. Parece-me, também, impossível reduzir o funcionamento das representações ao princípio objetivo da distância que separa leigos e médicos, detentores do saber dominante. De fato, a doença está hoje nas mãos da medicina, mas ela permanece sendo 
um fenômeno que a ultrapassa ${ }^{10}$. A interrogação sobre o sentido, em particular, não se reduz à informação médica - o diagnóstico - que aceitamos em numerosos casos. Em um plano mais geral, a história da medicina nos mostra de que modo as relações entre saber médico e concepções do senso comum podem estabelecer-se nos dois sentidos, sem uma dependência em sentido único, mas com vai-e-vens entre o pensamento erudito e o pensamento de senso comum $^{11}$.

Pode-se observar, por outro lado, que a leitura mais freqüentemente feita dos trabalhos de Boltanski tem sido extremamente reducionista e banalizante. Embora ele quisesse fazer a teoria do discurso sobre a doença, seu trabalho foi apreendido, essencialmente, por identificar uma percepção diferente da doença e dos fenômenos corporais nos membros das classes populares. Isso satisfez todos aqueles para quem a tarefa da sociologia se resume ao estudo da variação social dos mais diversos fenômenos.

Tomamos, pois, uma crítica feita com freqüência ao meu próprio trabalho: a de ser um estudo qualitativo, restrito a uma amostra de conveniência composta exclusivamente pelos membros das classes médias, ignorando a variação das representações segundo grupos sociais. Essa crítica é justificada, e os estudos posteriores na França e no exterior ${ }^{12}$, indicando tais diferenciações, foram importantes. Contudo, parece muito limitante reduzir o objeto da sociologia à demonstração da variedade das condutas, dos modos de pensamento, das linguagens etc., segundo classes sociais. A identificação dessas variações, por mais importantes que sejam, num sentido estrito, é secundária: deve vir num segundo tempo.

As críticas a princípio dirigidas aos estudos da representação social eram, portanto, parcialmente justificadas. De qualquer modo, elas deixavam de reconhecer o objetivo central desse tipo de estudo. Mas, curiosamente, em fins dos anos 70, uma mudança de perspectiva bastante surpreendente operou-se na sociologia. Assistimos a uma crise profunda dos esquemas explicativos globais, fundados sobre o primado das determinações socioeconômicas. O "sujeito" - sua experiência, o sentido que ele mesmo dá à sua ação - tornou-se objeto de estudo de máxima legitimidade. Ao mesmo tempo, o sociólogo começou a interrogar-se sobre sua posição em relação ao objeto de sua pesquisa. Tal mudança deveria satisfazer o pesquisador interessado no estudo das representações sociais, tanto mais que os estudos reclamando sua participação se multiplicaram. De fato, não podemos evitar certa inquietação: o retorno ao 
sujeito e ao sentido conduz freqüentemente a uma imprecisão perigosa, o "vivido" individual aparecendo como portador de virtudes inefáveis mas pouco explicitadas. A noção de representação, frequientemente empregada de modo muito frouxo, tornou-se um tipo de metanotação comum a todas as ciências sociais - encontrando-se, aliás, até em colunas de revistas -, designando qualquer conteúdo ideativo e podendo aplicar-se incondicionalmente a qualquer objeto ou situação. Seu emprego não tem mais ligação com a conceitualização inicial, que tinha numerosos embaraços e limites, mas que testemunhava um esforço de elaboração. Isso não tem, em si, muita importância, mas nenhuma outra construção teórica veio substituir, hoje, o emprego dessa noção.

Para terminar, após o recuo no tempo e a reflexão descrita aqui, esforçarme-ei por dizer quais são hoje, a meu ver, os limites da noção de representação social e as razões que fazem com que, não obstante esses limites, sua utilização ainda seja fecunda, em particular no campo da saúde e da doença. Hoje o principal limite parece residir na generalidade do nível de análise que a noção constitui. O mais das vezes, ela parte de um material verbal constituído, seja através de respostas a um questionário, seja através do discurso emitido em entrevistas individuais. Isso coloca, de início, o problema da mediação da representação pela linguagem. Mas, por outro lado, a partir desses discursos específicos, dessas expressões particulares, o pesquisador tenta apreender a lógica comum subjacente, o código partilhado, portanto mais geral, que se aplica a todas essas discussões, que é o nível das representações sociais. Acredito que exista aí um nível de análise específico, correspondente ao funcionamento de configurações sociocognitivas bastante globais, graças às quais o individual e o coletivo se interpenetram ${ }^{13}$. Marc Auge também define para as sociedades de linhagem, a "ideo-logic" como "a estrutura fundamental (a lógica sintática) de todos os discursos possíveis, numa sociedade dada, sobre essa sociedade" na qual se inscreve a diversidade das falas concretas (AUGÉ, 1975, p. 20).

Uma das tarefas do sociólogo pode ser indicar de que modo essas representações estão enraizadas na realidade social e histórica, ao mesmo tempo em que contribuem para construí-la. Assim, no que concerne às representações de saúde e doença que estudei, sem dúvida teria sido útil, primeiro, demarcar melhor a articulação dessas representações com a patologia de uma época e, em seguida, com uma configuração histórica e ideológica precisa: a visão rousseauniana das relações entre homem e natureza no fim do século XVIII e que dura ainda hoje. Enfim, teria sido necessário demonstrar melhor suas ligações com o sistema de relações coletivas que, através das leis sociais, através do 
desenvolvimento da medicina, institucionalizou-se progressivamente na medicina. Em trabalho recente, Janine Pierret e eu (HERZLICH \& PIERRET, 1984) tentamos ressituar as concepções de doença e de doente no conjunto desses fenômenos macrossociais: pareceu-nos que o recurso à história poderia constituir um caminho para a análise. Da mesma forma, o cruzamento das perspectivas sociológicas e antropológicas pode ter um caráter revelador ${ }^{14}$ : é em contrasteou às vezes por analogia - com as representações de outra sociedade que apreendemos melhor os caracteres e o funcionamento dessas configurações que denominamos de representações sociais.

Contudo, se nos situamos num tempo curto e no quadro exclusivo das sociedades industriais, algumas representações sociais podem ter enorme estabilidade. Por outro lado, a generalidade do nível de análise provavelmente reduz o interesse da noção, quando nos contentamos em utilizá-la numa perspectiva unicamente descritiva, sem estabelecer hipóteses precisas quanto a seus efeitos complexos numa situação dinâmica. Passados os estágios dos primeiros estudos, corre-se o risco de os seguintes se tornarem redundantes. $\mathrm{O}$ estudo das variações segundo grupos sociais ou segundo populações particulares podem certamente constituir um aporte. Mas, como disse, não me parece fundamental. Por outro lado, creio que o nível das representações deve ser levado em conta nos estudos de todas as situações em que apostas se desenham, evoluem e se redefinem na sociedade; em que debates se cristalizam; em que a tensão e o conflito aparecem ou se transformam em mobilizações e ações coletivas, que são todas correlativas de mudanças de sentido.

A este respeito, saúde e doença me parecem ter, além de elementos de estabilidade, características particulares que fazem delas objetos privilegiados, uma vez que são suscetíveis de metaforizá-las ou de engendrá-las.

Por ser um evento que ameaça ou modifica, às vezes irremediavelmente, nossa vida individual, nossa inserção social e, portanto, o equilíbrio coletivo, a doença engendra sempre uma necessidade de discurso, a necessidade de uma interpretação complexa e contínua da sociedade inteira. Essa forte exigência de discurso interpretativo me parece ser uma das condições de cristalização de uma representação estruturada. Por outro lado, nas representações da saúde e da doença aparecem, relacionadas, nas nossas visões do biológico e do social.

Referi-me à generalidade do fenômeno, que ultrapassa em muito nossa sociedade. Pode-se ficar surpreso com a evolução havida no curso das duas últimas décadas em relação ao impacto de nossas representações do biológico: 
a meu ver, a importância da doença, da saúde, do corpo, dos fenômenos biológicos como objetos metafóricos, como suportes do sentido de nossa relação com o social, aumentou consideravelmente nos últimos quinze anos. De um lado, a sociedade possui um discurso em que "a saúde" ocupa lugar central, ainda que muito ambíguo: R. Crawford (1980) pôde analisar o que ele denomina de "saudização" de nossa sociedade no nível de seus valores fundamentais. De outro lado, o modelo em curso na representação da saúde e da doença - o do indivíduo sadio em oposição ao indivíduo doente - estendeu-se, até incluir hoje a própria medicina. Esta última, e não mais a doença apenas, tornou-se metáfora do social e lugar de expressão privilegiada de nossa relação com ele.

Como a doença, a medicina é freqüentemente conflituada. Há vinte anos, na consciência coletiva, a sociedade nociva atacava o corpo do indivíduo e se encarnava na doença. Hoje, a sociedade e seus perigos parecem encarnarse também na medicina e em suas intervenções. Esta é epicentro de conflitos culturais e sociais, e em torno dele cristalizam-se algumas de nossas maiores interrogações vis-à-vis duas características da evolução social: de um lado, o lugar crescente da ciência e da técnica; de outro, a importância da "profissionalização" e do "laudo".

Essa evolução se encarnou, no curso dos últimos anos, numa grande variedade de práticas e de organizações, nos debates e movimentos coletivos e também nos encaminhamentos complexos e recíprocos entre saberes profissionais e discursos leigos. Seria extenso demais evocá-los aqui, mas tudo indica que existem diversas maneiras para uma representação coletiva - a da saúde e da doença em particular - tornar-se ativa no universo social. Desse ponto de vista, sem dúvida, podemos ser tentados a afirmar a fecundidade persistente dessa noção.

\section{Referências}

AIACH, P. Contenu de l'objet santé et variabilité des attitudes. Conceptions, mesures et actions em santé publique. Paris, Inserm, v. 103, p. 331-352, 1981.

AUGÉ, M.; HERZLICH, C. (Orgs.). Le sens du mal, anthropologie, histoire, sociologie de la maladie. Paris: Archives Contemporaines, 1984.

AUGÉ, M. Théorie des pouvoirs et idéologies. Paris: Herman, 1975.

BLAXTER, M.; PATERSON, E. Mothers and daughters: a three genera- 
tional study of health attitudes and behovior. London: Heineman, 1982.

BOLTANSKI, L. La découverte de la maladie: la diffusion du savoir medical. Paris: Centre de Sociologie Européenne, 1968.

BOURDIEU, P. Le sens pratique. Paris: Editions de Minuit, 1980.

BOURDIEU, P.; PASSERON, J. C.; CHAMBOREDON, J. C. Le métier sociologue. Paris: Mouton-Bordas, 1968.

BURY, M. R.; WOOD, P. H. Problems of communication in chronic illness. International Rehabilitation Medicine, v. I, p. 130-134, 1979.

CRAWFORD, R. Healthism and the medicalization of every day life. International Journal of Health Sciences,v. X, p. 365-388, 1980.

DOUGLAS, M. Purity and danger, an analysis of concepts of pollution and taboo. London: Routledge, 1966.

DURKHEIM, E. Les règles de la méthode sociologique. Paris: PUF, 1956, p. XXII.

DURKHEIM, E. Représentations individuelles, représentations collectives. In: . Sociologie et philosophie, Paris: PUF, 1967, p. 1-38.

HERZLICH C. La représentation sociale. In: MOSCOVICI S. (Org.). Introduction à la psychologie sociale. Paris: Larousse, 1972. p. 317-ss.

HERZLICH C. Santé et maladie, analyse d'une représentation sociale. Paris: La Haye, Mouton, 1969.

HERZLICH, C.; PIERRET, J. Malades d'hier, malades d'aujourd'hui. De la mort collective au devoir de guérison. Paris: Payot, 1984.

HERZLICH, C. Médécine moderne et quête de sens: la maladie signifiant social. In: AUGÉ, M.; HERZLICH, C. (Org.). Le sens du mal, anthropologie, histoire, sociologie de la maladie. Paris: Archives Contemporaines, 1984.

HEZLICH, C. Perceptions et représentations des usagers: santé, corps, handicaps.In: Conceptions, mesures et actions en Santé Publique. Paris, Inserm, v. 104, p. 131-352, 1981.

MOSCOVICI, S. La Psychanalyse, son image et son publique Paris: PUF, 1961.

SONTAG, S. Illness as metaphor. New York: Farrar, Strauss and Giroux, 1977. 
A Problemática da Representação Social e sua Utilidade...

\section{NOTAS}

${ }^{1}$ Tradução por Marilena Corrêa e revisão de Maria Andréa Loyola. Publicado em Physis Revista de Saúde Coletiva, v. 11, n. 2, 1991, p. 23-36.

${ }^{2}$ Socióloga, Centre de Recherche Médécine, Maladie et Sciences Sociales (CERMES). E-mail herzlich@vjf.cnrs.fr.

${ }^{3}$ Esta apresentação se fundamenta nos estudos de MOSCOVICI (1961) e de HERZLICH (1969). Para a discussão da representação social, ver também prefácio de MOSCOVICI (1961) a esta última obra, bem como HERZLICH (1972).

${ }^{4}$ DURKHEIM (1956, p. XXII). Ver também Durkheim (1967, p. 1-38).

${ }^{5}$ Reconheço, no entanto, que, em meu próprio estudo, o estatuto teórico dos modelos de conduta propostos foi insuficientemente discutido.

${ }^{6}$ Ver sobre esse assunto: HERZLICH (1972, p. 317-ss.).

${ }^{7}$ No prefácio à edição inglesa de meu livro Santé et maladie, analyse d'une représentation sociale, e em meu artigo "Perceptions et représentations dês usagers: santé, corps, handicaps".

${ }^{8}$ Com relação à crítica dos psicossociólogos, podemos afirmar também que se revelavam freqüentemente decepcionantes numerosos estudos fundados sobre as noções, aparentemente mais operacionais, de atitudes de opinião e de informação, nas quais se acreditava poder evidenciar a ligação direta com a conduta.

${ }^{9}$ Ver CRAWFORD (1980) citado em BOURDIEU, PASSERON \& CHAMBOREDON (1968). O grifo é meu. Para uma exposição das atuais posições de Pierre Bourdieu, ver, por exemplo, BOURDIEU (1980, p. 41).

${ }^{10}$ Ver, sobre este ponto, BOURDIEU (1980), assim como BURY \& WOOD (1979, p. 130134).

${ }^{11}$ No quadro desse estudo efetuei, aliás, algumas entrevistas com clínicos gerais, aplicando o mesmo roteiro de entrevista usado com os informantes leigos. Eles responderam sem nenhuma surpresa ou dificuldade e desenvolveram concepções muito próximas das dos indivíduos "recémchegados", i.e., dos outros entrevistados.

${ }^{12}$ Ver, na França, os trabalhos de A. d'Houtaud e P. Aiach. Ver também BLAXTER e PATERSON (1982). 
${ }^{13}$ Poderia ser feita uma outra interpretação dos discursos produzidos pelos entrevistados. É sabido que, com um talento às vezes notável, os entrevistados se colocam como teóricos da própria experiência. Aliás, movidos por mim nessa direção, forneciam um relato e elaboravam a análise desse relato. Desde esse estudo, a etnometodologia teorizou esse tipo de comunicação, bem como as regras de descrição e de interpretação cotidiana de eventos e de situações. Meu interesse pelas categorias, os agenciamentos cognitivos de interpretação da doença pelos sujeitos que entrevistei, coincidem em grande parte com o dos etnometodólogos, mas não pude aproveitar os avanços produzidos por seus trabalhos, que não estavam divulgados então na França (Studies in ethnometodology, de Harold Garfinkel, e The social organization of juvenile justice, de Aaron Cicourel, ambos de 1967). Eu estava, aliás, muito próxima da idéia de construção social da realidade, ainda que não houvesse lido nessa época o livro de Berger e Luckman (A construção social da realidade. Petrópolis: Vozes, 1983), que data de 1966 e também era praticamente desconhecido na França. Hoje, consciente dos pontos cegos de minha perspectiva, diria que, se a idéia de construção social me parece sempre fundamental (como mostra este texto), por outro lado as posições de etnometodologia, para a qual as interpretações da vida cotidiana são a base mesma da ordem social (esta não tendo, no fundo, existência independente das práticas descritivas e interpretativas imediatas), me parecem divergentes da minha perspectiva. Mas isto mereceria, seguramente, longos debates.

${ }^{14}$ Ver introdução a AUGÉ e HERZLICH (1984).

\section{ABSTRACT}

The concept of social representation ands its utility in the health care field

Focusing on work produced in France from the sixties on, the author reviews the ways in which Durkheim's concept of social representation has been updated within the health care field. While some theoretical limitations underlying the use of this concept are admitted, the author argues in favor of its continued fecundity as an analytical tool in studying phenomena of health care and illness. She also points to some theoretical developments that may possibly be achieved through use of the concept in this particular field.

Key words: Social representation; health; illness. 